\title{
O Sério e o Lúdico: Um Jogo para o Ensino e a Aprendizagem de Práticas do 5S para Crianças
}

\author{
Juliano Pires Soares, Carlos Eduardo Pes Gomes, Cristina Paludo Santos \\ Universidade Regional Integrada do Alto Uruguai e das Missões (URI) \\ 98.802-470 - Santo Ângelo - RS - Brasil
}

jpsjuliano218@yahoo.com.br, carlospesgomes@hotmail.com, paludo@san.uri.br

\begin{abstract}
This paper presents the game Desafio dos 5S, aimed at the children 's audience, whose purpose is to teach, reinforce and encourage children to practice healthy habits by making use of the Japanese philosophy referenced as 5S Program. The methodology used to design the game, as well as the results obtained from its availability to children are presented so that they can be enriched or replicated.
\end{abstract}

Resumo. Este artigo apresenta o jogo Desafio dos $5 S$, voltado ao público infantil e que tem por objetivo ensinar, reforçar e incentivar as crianças à prática de hábitos saudáveis fazendo uso da filosofia japonesa referenciada como Programa 5S. A metodologia empregada para a concepção do jogo, bem como os resultados obtidos a partir de sua disponibilização para crianças são apresentados para que possam ser enriquecidos ou replicados.

\section{Introdução}

O desenvolvimento tecnológico aliado a abertura das escolas para novas práticas de ensino, têm impulsionado a concepção de jogos educacionais computadorizados como uma forma de prover meios para produção e construção do conhecimento pelo aluno (Pietruchinski, 2011). Tais jogos podem se inserir em diversas atividades, as quais não estão voltadas apenas para o desenvolvimento de conteúdos específicos, mas também de habilidades que enriquecerão a formação geral do aluno auxiliando-o a ampliar sua linguagem e promover a comunicação de ideias; adquirir estratégias de resolução de problemas e de planejamento de ações; estimular a concentração, raciocínio, perseverança e criatividade; estimular a compreensão de regras, fixação de conceitos, dentre outros.

Os jogos educacionais, quando voltados ao público infantil, além de fazerem uso de recursos lúdicos para estimular e prender a atenção da criança, extrapolam a ideia de entretenimento e oferecem outros tipos de experiência nos quais a educação, em suas várias formas, é o objetivo principal. Nesta categoria de jogos insere-se o Desafio dos 5S - um jogo sério que baseia-se na filosofia do Programa $5 \mathrm{~S}$ e visa, a partir de simulações de situações práticas do dia-a-dia, incentivar as crianças à prática de hábitos saudáveis como forma de promover mudanças nas relações das pessoas consigo mesmas, com os outros e com a natureza.

O Programa 5S, originário do Japão pós-guerra, é formado por cinco palavras japonesas iniciadas pela letra S (Seiri, Seiton, Seiso, Seiketsu e Shitsuke) (Lapa, 1998). No Brasil, o Programa é conhecido com acréscimo da palavra "Senso" antes de cada expressão, que tenta representar o conteúdo daquele termo específico: Seiri - Senso de Utilização / Seleção / Descarte; Seiton - Senso de Ordenação / Organização / Arrumação / Ordem; 
VI Congresso Brasileiro de Informática na Educação (CBIE 2017)

Anais do XXIII Workshop de Informática na Escola (WIE 2017)

Seisou - Senso de Limpeza / Asseio; Seiketsu - Senso de Saúde / Bem estar / Higiene; Shitsuke - Senso de Autodisciplina / Ordem mantida.

Neste sentido, a proposta do jogo Desafio dos $5 \mathrm{~S}$ é que as crianças aprendam e reproduzam esses conceitos em suas atividades, tornando-se multiplicadores destas práticas, técnicas e ideias. Tudo isso, através da formação da cultura. Uma descrição mais detalhada do jogo desenvolvido, bem como dos resultados obtidos a partir da sua disponibilização para crianças são apresentadas nas seções subsequentes.

\section{Metodologia}

O jogo Desafio dos $5 \mathrm{~S}$ procura desencadear ações que possibilitem a oportunidade de aprender e incorporar comportamentos fundamentais, exigidos tanto na vida social como na vida profissional, tais como: organização, disciplina, iniciativa, pró-atividade, responsabilidade e compartilhamento de propósitos. Para tanto, faz uso de cenários do cotidianos e ilustrações que evidenciam as mudanças de comportamento desejadas a fim de demonstrar para as crianças como cada um dos $5 \mathrm{~S}$ pode ser praticado.

A Figura 1 apresenta as interfaces iniciais do Desafio dos 5S. A dinâmica do jogo envolve a execução de 5 desafios, sendo que para cada um deles são apresentados 6 cenários distintos. Ao alcançar o término do jogo o jogador terá cumprido 30 atividades explorando situações diversas relacionadas aos 5S. A cada " $\mathrm{S}$ " selecionado o jogador recebe explicações sobre o seu significado e quais os benefícios providos pela sua utilização. Além disso, terá que executar ações de modo a praticar o $\mathrm{S}$ escolhido. As explicações do jogo são providas no formato de áudio pelo personagem nomeado Ryou.

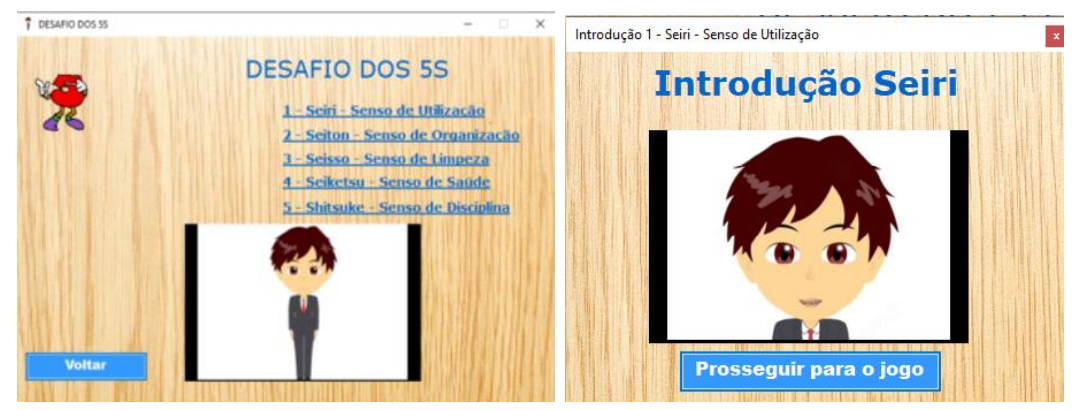

Figura 1. Interfaces iniciais do jogo Desafio dos $5 S$

A Figura 2 apresenta exemplos de atividades que envolvem os 5 desafios do jogo. A Figura 2(a) apresenta um cenário em que a criança deverá utilizar o seu "Senso de Utilização - SEIRI'. Ter o bom senso de utilização significa dar um jeito nas coisas desnecessárias, mesmo que tenham valor, mantendo apenas as que são úteis e direcionando as inúteis para onde possam ser utilizadas. Neste cenário a criança deverá elencar o que é útil ou inútil no ambiente. A cada objeto inútil eliminado do ambiente a criança recebe uma pontuação como recompensa ao seu bom senso. É importante destacar que o senso de descartar não significa exclusivamente jogar as coisas fora, mas sim prover um fim adequado a elas por meio de um processo de classificação (reciclagem, doações, venda, etc).

Já, a Figura 2(b) apresenta um exemplo de atividade relacionada ao "Senso de Ordenação/Organização - SEITON”. Ter o bom senso de ordenação significa deixar os materiais que serão utilizados sempre disponíveis e em lugar adequado. $\mathrm{O}$ ato de ficar 
procurando provoca atraso, gerando desperdício de tempo. É necessário, portanto, praticálo diariamente para encontrar imediatamente qualquer material.

A Figura 2(c) ilustra uma atividade onde o jogador deverá usar o "Senso de Limpeza - SEISOU", conservando limpo o ambiente de estudo, trabalho, moradia e lazer. A Figura 2(d) exemplifica as atividades relacionadas ao "Senso de saúde - SEIKETSU". Ter o bom senso de saúde significa praticar os três primeiros "S" (Seleção/Utilização, Ordenação e Limpeza), conservando-os diariamente até tornarem-se hábito, que proporcionará a manutenção de todos os itens já aplicados, com mais saúde e ambientes mais agradáveis. Na escola este comportamento inclui cuidar de sua aparência pessoal; lavar a mãos antes de fazer lanche; cuidar do material escolar, dentre outros. Já, em casa, não deixar latas cheias de água no jardim, manter a casa arejada e limpa; não fazer as refeições sobre a cama, etc. Estes cenários estão presentes no jogo procurando demonstrar a necessidade de comportamentos saudáveis.

Por fim, a Figura 2(e) apresenta uma das atividades relacionadas ao "Senso de Auto-disciplina - SHITSUKE", onde são ressaltados que para ter o bom senso de autodisciplina significa manter os bons hábitos e as boas maneiras adquiridos, ou seja, praticar espontaneamente os quatro "S", sem precisar que outra pessoa o lembre e o cobre. É habituar-se a praticar a Seleção, Ordenação, Limpeza e Conservação.
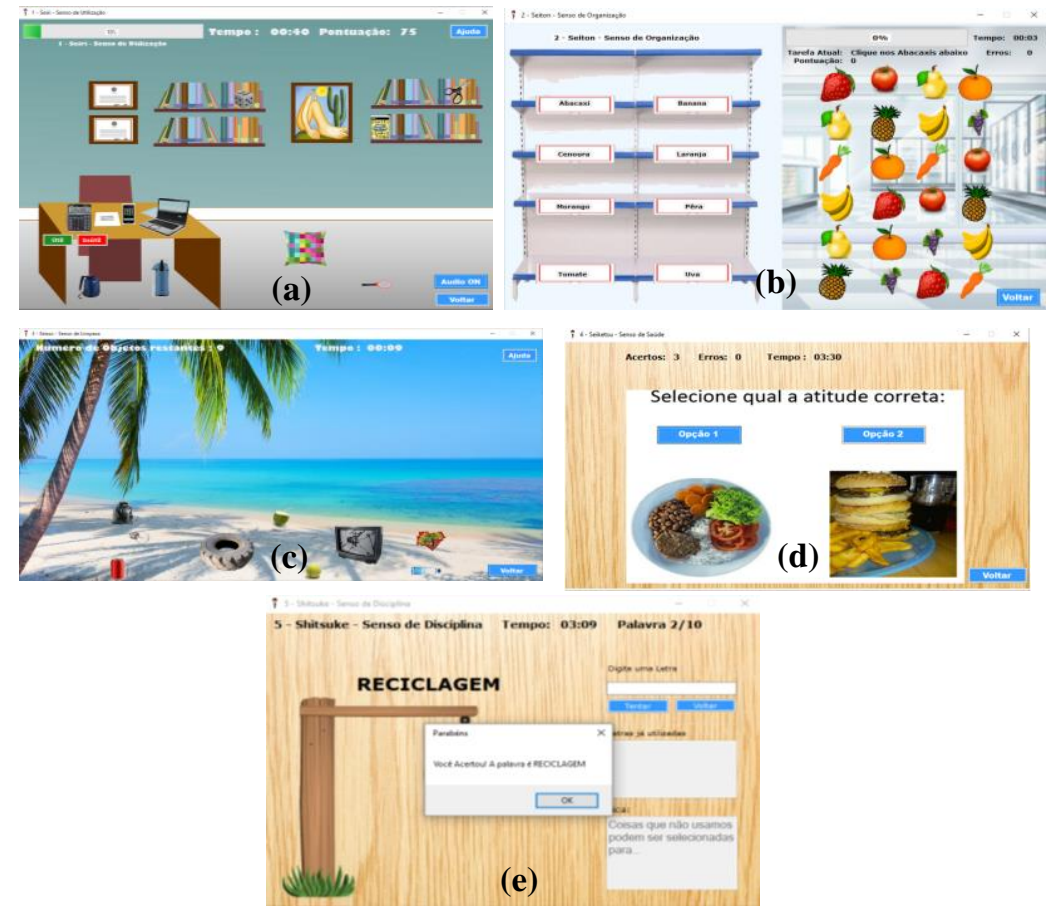

Figura 2. Cenários do jogo Desafio dos $5 \mathrm{~S}$

Entende-se que o desenvolvimento de recursos computacionais educacionais envolve conceber a ideia, desenvolvê-la e avaliar a experiência adquirida. Sendo assim, a participação ativa dos estudantes no processo avaliativo é extremamente importante por trazer um retorno sobre os métodos aplicados, podendo ser realizadas mudanças no emprego da metodologia abordada e a melhoria contínua, a fim de garantir mecanismos para uma aprendizagem significativa (França e Tesdeco, 2015). Desta maneira, o Desafio dos $5 S$ foi avaliado em um ambiente real, sendo os resultados obtidos apresentados a seguir. 
VI Congresso Brasileiro de Informática na Educação (CBIE 2017)

Anais do XXIII Workshop de Informática na Escola (WIE 2017)

\section{Resultados}

O processo avaliativo foi realizado com a participação de 22 estudantes na faixa etária entre 8 a 10 anos, matriculados no ensino fundamental. Os responsáveis pelas crianças participantes assinaram termos de consentimento, em especial para autorizar registros fotográficos. Tal processo foca na reação das crianças ao utilizarem o jogo, com vistas a verificar se este é motivador para ser usado como material de aprendizagem; proporciona uma boa experiência de uso; e gera uma percepção de utilidade educacional. Os dados foram analisados qualitativamente, através das anotações de campo, identificando as principais dificuldades apresentadas pelas crianças durante a interação. A Figura 3 apresenta alguns registros fotográficos da avaliação realizada.
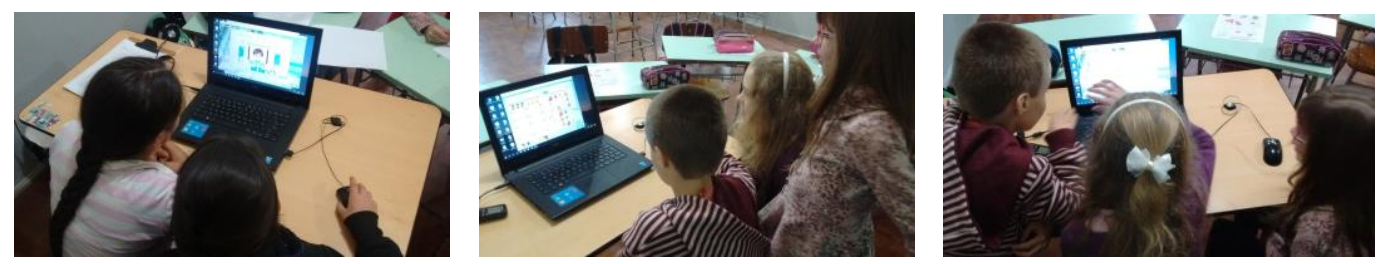

Figura 3. Desafio dos $5 \mathrm{~S}$ em processo de avaliação pelos usuários

Uma vez disponibilizado o jogo as crianças ficaram extremamente motivadas, demonstraram gostar da interface e afeiçoaram-se ao personagem Ryou. Ao finalizar a fase de avaliação as crianças pediram para voltar outras vezes para que pudessem jogar novamente. Já, no que se refere à complexidade conceitual, as atividades relacionadas aos 4 primeiros desafios foram consideradas fáceis pelas crianças, porém ao se depararem com as atividades propostas no desafio 5 a maioria das crianças $(87 \%)$ passou a pedir ajuda constantemente o que gerou certa frustação. As atividades desta etapa compreendem a formulação de perguntas relacionadas às atividades anteriores e as crianças precisam encontrar a palavra que representa a resposta correta, similar ao jogo da forca. Neste caso constatou-se que existem falhas referentes à forma como as questões foram elaboradas, sendo muitas vezes utilizados termos desconhecidos pelos jogadores. Mesmo as crianças maiores apresentaram dificuldades na compreensão da pergunta. Isso induz a necessidade de ajustes considerando este aspecto.

Outros ajustes a serem realizados estão relacionados com as atividades do desafio 3 (senso de limpeza). Em $85 \%$ dos relatos as crianças destacam que as atividades estão muito curtas e que rapidamente conseguem passar de fase. Gostariam que houvessem maiores desafios a serem cumpridos nesta etapa do jogo.

Os resultados decorrentes da avaliação do jogo Desafio dos 5s revelam alguns aspectos-chave que induzem a novas escolhas de design e, reforçam a importância do envolvimento do público-alvo em avaliações de software, ainda negligenciado em vários processos de desenvolvimento. Entende-se que são necessárias investigações longitudinais para avaliar o quanto as crianças adotaram os comportamentos incentivados pelo uso do jogo, no entanto, isto requer uma metodologia de avaliação diferenciada. Além disso, por se tratar de um método educativo, de médio e longo prazo, não se podem esperar resultados imediatamente após o seu uso, especialmente por envolver a mudança de mentalidade e comportamento. Paciência e perseverança são fundamentais para o desenvolvimento constante do programa.

Neste primeiro momento, o que se pretendeu foi avaliar o quanto os cenários produzidos despertam o interesse do público-alvo e são efetivos quanto aos objetivos aos 
VI Congresso Brasileiro de Informática na Educação (CBIE 2017)

Anais do XXIII Workshop de Informática na Escola (WIE 2017)

quais se propõem. Quanto a estes requisitos pode-se afirmar que os resultados foram positivos e as avaliações realizadas permitem que novos cenários possam ser elaborados de forma a reforçar o valor das atitudes para a vida.

\section{Considerações Finais e Direcionamentos Futuros}

Apesar de vários relatos da aplicação do programa 5s em empresas (Gomes, 2012)(Pires, 2014) e em escolas (Da Silva, 2013)(Floriano, 2017), a maioria das experiências envolvem oficinas constituídas de aulas expositivas de forma adaptada ao nível de escolaridade dos participantes ou cartilhas sobre os conceitos, importância e possibilidades de utilização do 5s. Não se identificou experimentos que envolvam a abordagem adotada neste artigo direcionada ao desenvolvimento de um jogo e, acima de tudo, voltado ao público infantil. Isso caracteriza o aspecto inovador da proposta apresentada.

Acredita-se que apresentar o programa 5S para crianças envolve disseminar práticas para uma melhor qualidade de vida, incentivando-os e tornando-os multiplicadores desse conhecimento em seus meios de convivência e lhes permitindo compreender que a ferramenta estudada pode contribuir para boas práticas de organização, limpeza e saúde, o que promove contribuições na vida de cada um e da sociedade.

Para concluir destacam-se as seguintes vantagens da prática do programa 5S: mudança do comportamento e dos hábitos das pessoas; aperfeiçoamento na forma de pensar e agir no dia-a-dia; respeito aos semelhantes e desenvolvimento pessoal; melhoria no ambiente de estudo e trabalho; melhoria no aproveitamento de tempo e recurso; educação para o cuidado com o meio ambiente; eliminação do desperdício e, incentivo à criatividade.

\section{Referências Bibliográficas}

DA SILVA, Elaine Patussi; DELES, Katarinny Pinto Sena; DE PAULA, Vérica Marconi Freitas. Implantação do programa 5S em uma escola municipal. Em Extensão, v. 12, n. 2, p. 128-140, 2013.

FLORIANO, Mikaela Daiane Prestes et al. TODOS PELA QUALIDADE: ENSINANDO GESTÃO AOS ALUNOS DA ESCOLA ESTADUAL NOSSA SENHORA DO LIVRAMENTO. Anais do Salão Internacional de Ensino, Pesquisa e Extensão, v. 8, n. $3,2017$.

FRANÇA, Rozelma; TEDESCO, Patrícia. Desafios e oportunidades ao ensino do pensamento computacional na educação básica no Brasil. In: Anais dos Workshops do Congresso Brasileiro de Informática na Educação (CBIE). 2015. p. 1464.

GOMES, Duarte Sousa Ferreira. Jogos Sérios para Lean Manufacturing: "Jogo: Método 5S". 2012. Tese de Doutorado. Instituto Politécnico do Porto. Instituto Superior de Engenharia do Porto.

LAPA, Reginaldo Pedreira. Programa 5S. Rio de Janeiro: Qualitymark, 1998.

PIETRUCHINSKI, Monica Hoeldtke et al. Os jogos educativos no contexto do SBIE: uma revisão sistemática de Literatura. In: Brazilian Symposium on Computers in Education (Simpósio Brasileiro de Informática na Educação-SBIE). 2011.

PIRES, Carla João Matos. Aplicação do programa $5 S$ visando a melhoria contínua da qualidade. MS thesis. Universidade de Aveiro, 2014. 